\title{
Investigation of the Switched Inductor Circuit for Harmonics Compensation
}

\author{
Maria C. Argyrou \\ Department of Electrical \\ Engineering, Computer \\ Engineering and Informatics, \\ Cyprus University of Technology, \\ Limassol, Cyprus \\ mx.argyrou@edu.cut.ac
}

\author{
CC Marouchos \\ Department of Electrical \\ Engineering, Computer Engineering and \\ Informatics \\ Cyprus University of Technology \\ Limassol, Cyprus \\ christos.marouchos@cut.ac.cy
}

\author{
M. Darwish \\ Brunel University/School of \\ Engineering and Design \\ London, UK \\ Mohamed.Darwish@brunel.ac.uk
}

\author{
Eftihia Iosif \\ Department of Electrical Engineering \\ Computer Engineering and Informatics, \\ Cyprus University of Technology, \\ Limassol, Cyprus \\ felicity-1@hotmail.com
}

\author{
F. Paterakis \\ Technological Educational Institute \\ of Athens, Department of \\ Electronic Engineering, Greece \\ fpatera@teiath.gr
}

\begin{abstract}
The switched inductor is a new circuit configuration for electronically varying the effective inductance of an inductor. In conjunction with a capacitor, filters with electronically adjustable tuning frequency can be constructed. This filter has the advantage to follow specific harmonics at the output of an inverter with varying frequency. In this way selective harmonic elimination is possible.
\end{abstract}

Index Terms-- Active filters, Switched capacitors, harmonic current elimination

\section{INTRODUCTION}

Voltage and current harmonics are always present in power converters. The line current is rich in odd harmonics and various solutions have been suggested [1-5]. The output of inverters contains unwanted voltage harmonics and many attempts are made to alleviate this problem [6-11]. In this paper a new active filter, the Switched Inductor Filter is first investigated, analyzed and then applied at the output of an inverter. The single pulse 3-level inverter, rich in low order harmonics is chosen to demonstrate the effectiveness of the filter.

The switched inductor is demonstrated in Fig. 1. It will be shown that the effective inductance $L_{\text {eff }}$, the inductance appearing at the input of the circuit, is smoothly controlled by setting the value of the duty cycle of the series switch S1, Fig. 3.

The circuit is first analyzed using the switching function technique [12] in order to derive an expression for the value of the effective inductance as a function of the duty cycle. A capacitor is used both in series Fig. 4, and in parallel Fig. 6, with the switched inductor and the response of the two circuits with varying duty cycle is investigated. Tuning is achieved in the same way as in passive filters but in the switched inductor circuit the tuning frequency is set by the value of the duty cycle of the series switch for fixed values of $L$ and $C$. The series tuned circuit is connected across the output of a single pulse 3-level inverter Fig. 8, in order to reduce the $5^{\text {th }}$ harmonic of the voltage. An inductor $L s$ is inserted in series in order to develop the opposing voltage to the voltage harmonics. It will be shown that the filter is very effective.

\section{OPERATION OF THE SWITCHED INDUCTOR}

The inductor is connected to the voltage source via a semiconductor switch. A second switch is connected across the inductor itself, Fig. 1. The two switches are working in antiparallel i.e. when one is open the other is closed, Fig. 2.

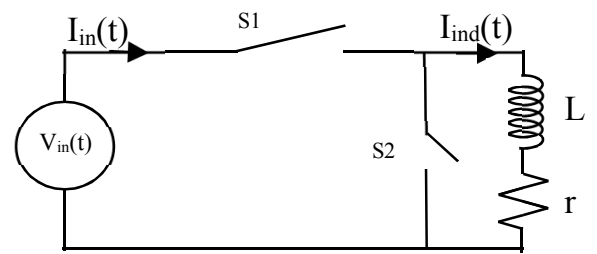

Fig. 1. The switched Inductor.

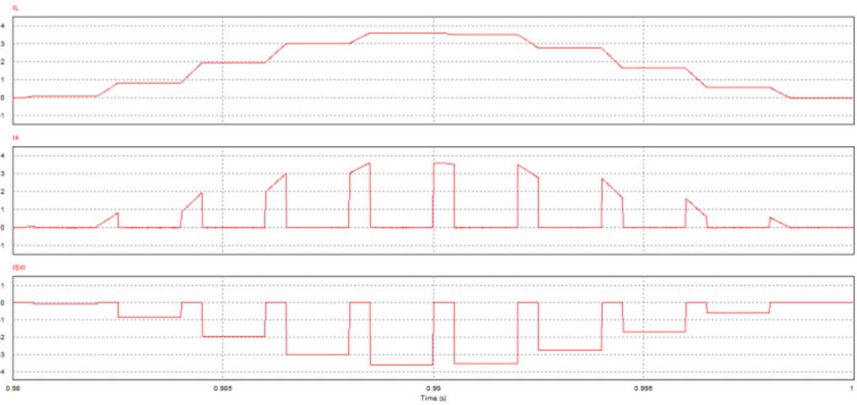

Fig. 2. Currents of the switched Inductor. Upper Trace: current through inductor. Middle Trace: Line Current. Lower Trace: Current through parallel Switch. 
The magnitude of the flowing current and hence the impedance of the circuit is controlled by controlling the duty cycle of the series switch S1, and consequently the effective impedance of the switched combination.

When the switched inductor is used in conjunction with a capacitor, the tuning frequency is electronically controlled making the combination suitable as a filter for eliminating harmonics in power electronic circuits.

\section{MATHEMATICAL ANALYSIS Of THE SWITCHED INDUCTOR}

The output voltage [12], the voltage across the inductor, $\mathrm{U}_{\mathrm{o}}(\mathrm{t})$ is given by

$$
U_{o}(t)=F(t) V_{\text {in }}(t)
$$

Where, $V_{\text {in }}(t)$ is the input voltage and

$$
V_{\text {in }}(t)=V_{p} \sin (\omega t)
$$

$\mathrm{V}_{\mathrm{p}}$ is the peak value of mains voltage, and $\mathrm{F}(\mathrm{t})$ is the switching function describing the switching action of the switch S1.

$$
F(t)=K_{o}+2 \sum_{n=1}^{\infty} \frac{\sin (n \delta)}{n \pi} \sin (\omega t-n \theta)
$$

Where, $\delta$ is the half width of the pulse, $\theta$ is the phase delay of the switching function and $n$ is a positive integer $1,2,3 \ldots$. $\mathrm{K}_{\mathrm{o}}$ is the average value of the switching function where, $\mathrm{K}_{0}=2 \delta / \mathrm{T}$ and $\mathrm{T}=$ mains period.

Therefore from (1)

$$
\begin{aligned}
& U_{o}(t)=K_{o} V_{p}+2 V_{p} \sum_{n=1}^{\infty} \frac{\sin (n \delta)}{n \pi} \sin [(n+1) \omega t-n \theta]+ \\
& 2 V_{p} \sum_{n=1}^{\infty} \frac{\sin (n \delta)}{n \pi} \sin [(n-1) \omega t-n \theta]
\end{aligned}
$$

The voltage $U_{o}(t)$ is applied to the inductor with inductance $L$ and small resistance $r$.

$$
U_{o}(t)=L \frac{d[I(t)]}{d t}+I(t) r
$$

Equation (5) is a linear non-homogeneous first-order differential equation with constant coefficients. The corresponding auxiliary equation

$$
L \lambda+R=0
$$

Results in a complementary function

$$
I_{h}(t)=e^{-r t / L}
$$

While the method of undetermined coefficients results in a particular integral giving a general solution

$$
I(t)=I_{h}(t)+I_{p}(t)=\ldots
$$

Note that, $I_{h}(t)$ is the transient, while $I_{p}(t)$ is the steadystate of the system.

$$
\begin{aligned}
& I_{\text {ind }}=K o \frac{V_{p}}{Z_{1}} \sin (\omega t-\varphi)+ \\
& \sum_{n=1}^{\infty} 2 \frac{V_{p} K_{n}}{Z_{n+1}} \sin \left[(n+1) \omega t-n \varphi_{n+1}\right]- \\
& 2 \frac{V_{p} K_{n}}{Z_{n-1}} \sin \left[(n-1) \omega t-n \varphi_{n-1}\right]
\end{aligned}
$$

Where,

$$
\begin{aligned}
& Z_{1}=\sqrt{[\omega L)]^{2}+r^{2}} \\
& Z_{n+1}=\sqrt{[\omega L(n+1)]^{2}+r^{2}} \\
& Z_{n-1}=\sqrt{[\omega L(n-1)]^{2}+r^{2}} \\
& \phi_{n+1}=a \tan \frac{\omega L(n+1)}{r} \\
& \phi_{n-1}=a \tan \frac{\omega L(n-1)}{r} \\
& \phi=a \tan \frac{\omega L}{r} \\
& K_{n}=\frac{\sin (n \delta)}{n \pi}
\end{aligned}
$$

In a real inductor the value of $r$ is very small and can be ignored. Furthermore, switching at relatively higher frequency than the mains frequency, the fundamental current in the inductor can easily be filtered and the expression of the current is reduced to

$$
I_{\text {ind }}(t)=K_{o} \frac{V_{p}}{w L} \sin \left(\omega t-90^{\circ}\right)
$$

The inductor current $I_{\text {ind }}(t)$ is "reflected" [12] back to the line, to form the line current $\mathrm{I}_{\text {Line }}(\mathrm{t})$ where,

$$
I_{\text {Line }}(t)=F(t) I_{\text {ind }}(t)
$$

The fundamental current is extracted from (12) as

$$
I_{\text {Line }}(t)=K_{o}^{2} \frac{V_{p}}{\omega L} \sin \left(\omega t-90^{\circ}\right)
$$

The "effective reactance" at fundamental frequency is derived from (13) as

$$
X_{\text {Leff }}=\frac{\omega L}{K_{o}^{2}}
$$


And the effective inductance

$$
L_{e f f}=\frac{L}{K_{o}^{2}}
$$

Therefore, the effective inductance of a fixed inductor can be controlled electronically Fig. 3, by controlling the duty cycle of the switches.

The resonance frequency of either in series or parallel circuit, ignoring $r$ is given as

$$
f_{r}=\frac{1}{2 \pi \sqrt{L C}}
$$

It follows that for a series $L C$ circuit employing the switched inductor where its effective inductance is given by (15), the resonance frequency becomes a function of both the passive elements $L C$ and the duty-cycle of the switches $\mathrm{K}_{0}$.

$$
f_{r}=\frac{K_{o}}{2 \pi \sqrt{L C}}
$$

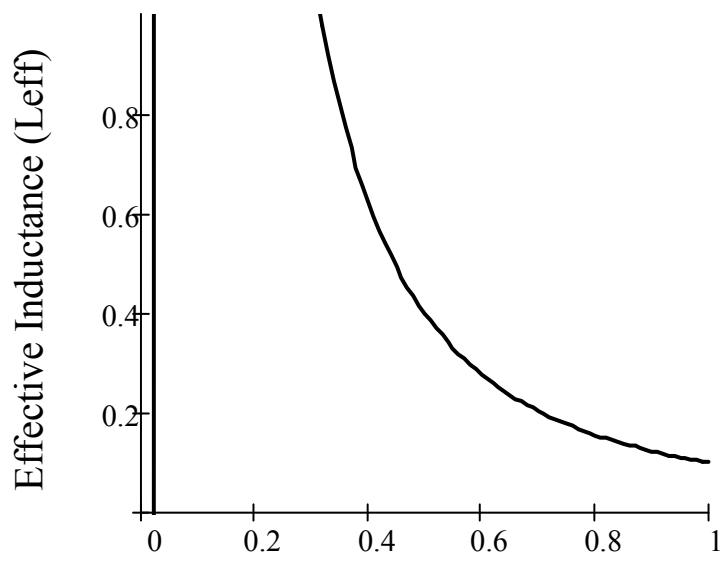

Duty Cycle (Ko) of the Switch S1

Fig. 3. Control of the inductance with the duty cycle of the switch.

\section{THE SWITCHED INDUCTOR}

\section{A. Series Tuned Circuit}

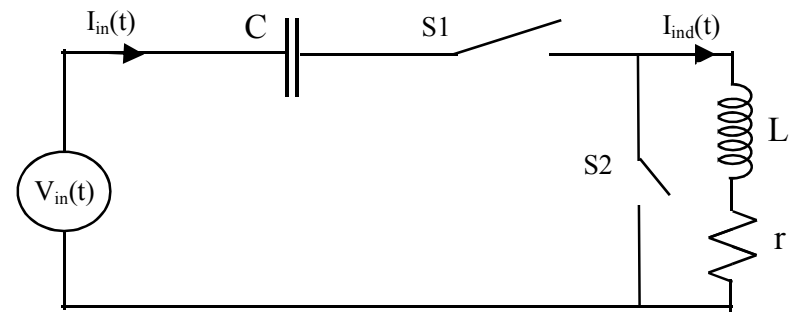

Fig.. 4. The series tuned circuit with switched inductor.

The switched inductor is connected in series with a fixed capacitor $\mathrm{C}=1.0 \mu \mathrm{F}$ Fig. 4 . The passive value of the inductor is $0.1 \mathrm{H}$ and it would give resonance at $503.3 \mathrm{~Hz}$. Now the tuning frequency can be set to any value up to $503.3 \mathrm{~Hz}$ by setting the duty-cycle $\mathrm{K}_{\mathrm{o}}$ according to (17) as shown in Table I.
By varying the duty cycle of the switches, resonance is achieved at $250 \mathrm{~Hz}$ for $\mathrm{K}_{\mathrm{o}}=0.5 \mathrm{Fig}$. 5 . The sharpness of the response is a function of the relative values of $L C$ as in any passive $L C$ series circuit. This is shown by repeating the response with a new set of values $\mathrm{L}=0.01 \mathrm{H}$ and $\mathrm{C}=10 \mu \mathrm{F}$, Fig. 5.

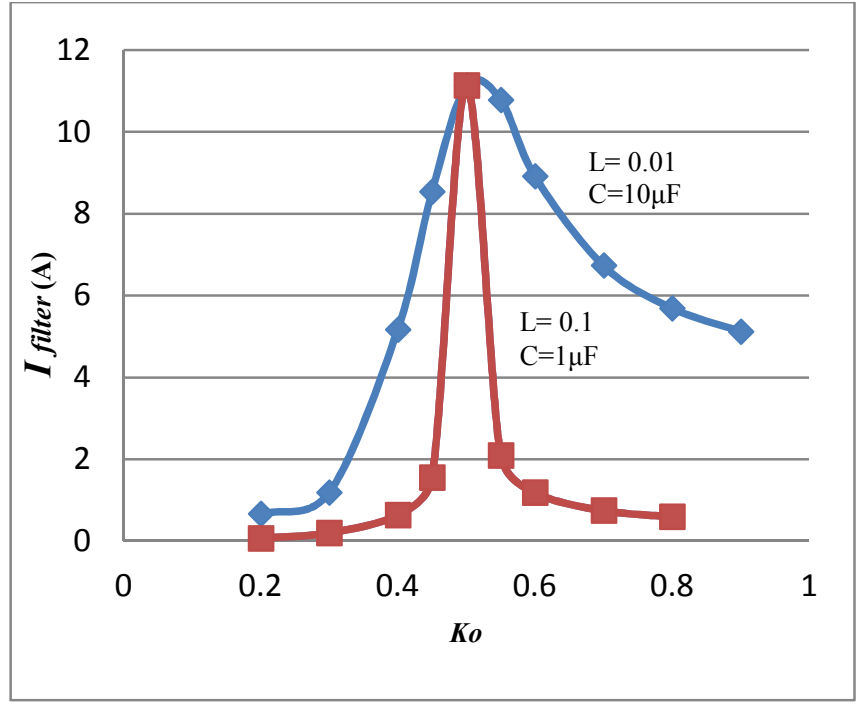

Fig. 5. Resonance: Current versus duty cycle at $250 \mathrm{~Hz}$.

TABLE I

VALUES OF $\mathrm{K}_{\mathrm{o}}$ AT DifFERENT RESONANCE FREQUENCIES

\begin{tabular}{|c|c|}
\hline Tuning frequency $(\mathrm{Hz})$ & $\boldsymbol{K}_{\boldsymbol{o}}$ \\
\hline $150 \mathrm{~Hz}$ & 0,298 \\
\hline $250 \mathrm{~Hz}$ & 0,497 \\
\hline $350 \mathrm{~Hz}$ & 0,695 \\
\hline
\end{tabular}

\section{B. Parallel Tuned Circuit}

In this circuit, the switched inductor is connected in parallel with a fixed capacitor Fig. 6. The passive value of the inductor would give resonance at a frequency according to (16) but now the tuning frequency can be set to any value by setting the duty-cycle $K_{o}$ according to (17) since for small values of $r$ the tuning frequency for series and parallel circuits is the same.

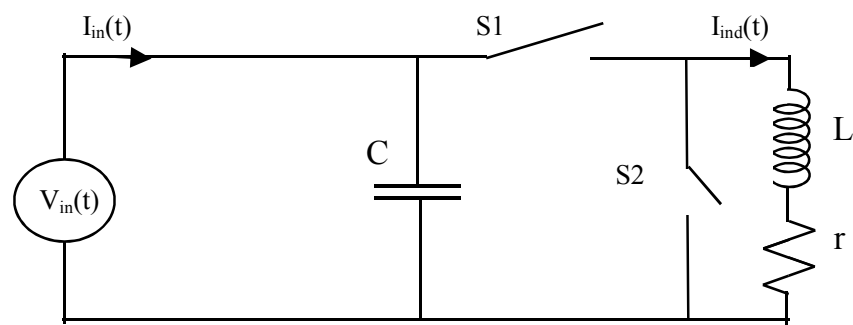

Fig. 6. The parallel tuned circuit with switched inductor.

In Fig. 7, the response of the circuit for $\mathrm{L}=0.1 \mathrm{H}$ and $\mathrm{C}=1.0 \mu \mathrm{F}$ is illustrated. The frequency of the supply voltage in Fig. 6 , is $250 \mathrm{~Hz}$ and for this frequency the current is 
minimum, practically zero for a duty-cycle of 0.5 according to (17). Again the tuning frequency can be set by the duty cycle. This circuit will present very high impedance to a selected frequency.

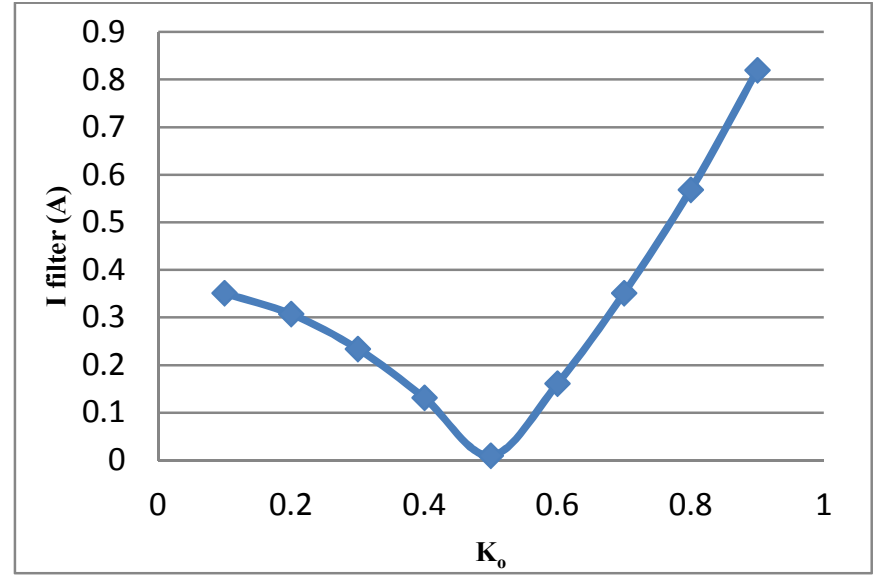

Fig. 7. Current against duty-cycle $\mathrm{K}_{\mathrm{o}}(\mathrm{L}=0.1 \mathrm{H}, \mathrm{C}=1 \mu \mathrm{F})$.

\section{AN APPLICATION: ELIMINATION OF VOLTAGE HARMONICS}

The switched inductor filter is connected at the output of an H-Bridge 3-Level single pulse inverter Fig. 8. A series inductor is inserted at the output where the harmonic voltage will be created in opposition to the harmonic voltage at the output of the inverter.

By tuning the filter at $250 \mathrm{~Hz}$, the fifth harmonic of the output voltage is almost eliminated Fig. 9. In Fig. 9, both the compensated and uncompensated output voltage is displayed.

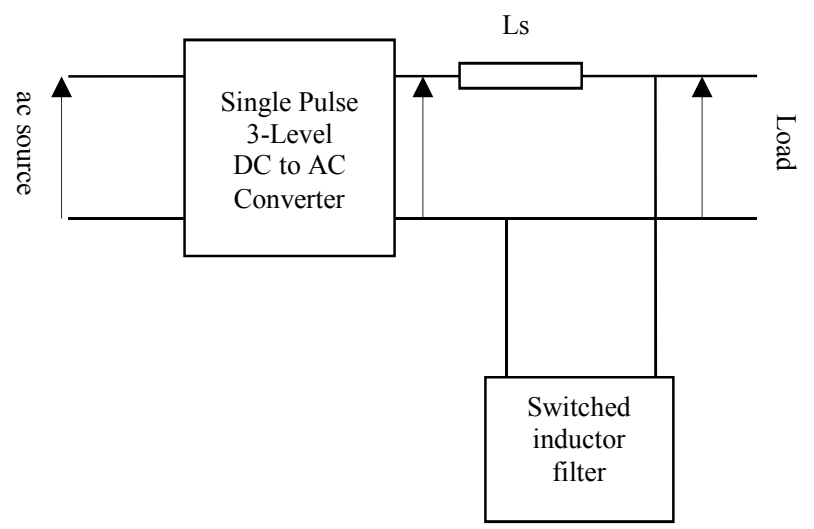

Fig. 8. The H-Bridge 3-Level single pulse inverter with the filter.

The filter is tuned at $250 \mathrm{~Hz}$ by setting the value of the duty cycle of the switch S1 to 0.5 according to Table I and (17). As shown, the 5th harmonic is almost eliminated. This is achieved because the filter draws harmonic current at that frequency and this current flow through the series inductance $L s$. The developed harmonic voltage is opposing the harmonic voltage of the inverter. Of course, part of the reduction is due to the series inductor itself.

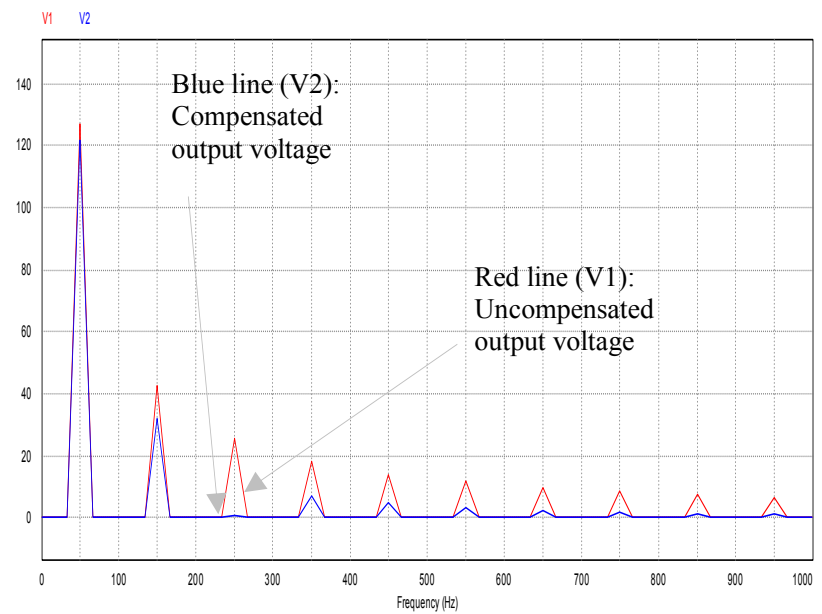

Fig. 9. Elimination of 5th harmonic of output voltage.

\section{CONCLUSIONS}

A new active filter is introduced here based on the switched inductor. It is demonstrated that series and parallel resonance is achieved at a selected frequency by setting the duty cycle of the series switch. The resonance frequency can be set to any value equal and below the frequency set by the fixed values of the inductance and capacitance in the circuit.

In order to demonstrate the effectiveness of the circuit, the series tuned circuit is used to reduce a selected voltage harmonic at the output of a 3-level single pulse inverter. The harmonic to be reduced is chosen electronically by setting the duty cycle of the series switch. It is shown that the filter is capable to reduce dramatically the selected harmonic. The usefulness of the circuit lies in the fact the filter can follow the harmonic as it changes frequency as is the case of an inverter supplying an ac-motor with variable speed.

The mechanism of reducing the output voltage harmonics of the inverter is to draw harmonic current through the series inductor. This is done by tuning the switched inductor filter at the frequency at the undesired harmonic. The filter is offering minimum impedance at that frequency and current flows through the series inductor. The developed harmonic voltage is opposing the harmonic voltage at the output of the inverter.

The most difficult point to realize the proposed circuit is losses. The current is interrupted at a switching frequency which has to be much higher than the harmonic the filter is aiming to eliminate. The switching frequency gives rise to losses. Furthermore timing is important: the charged inductor must always be in a closed circuit. This implies that the two semiconductor switches must never open in a way to have an open circuit for the inductor.

The parallel combination is still to be investigated for an application to alleviate the problem of harmonics.

\section{REFERENCES}

[1] H. Akagi, "Active harmonic filters". Proceedings of the IEEE, vol. 93, $\mathrm{n}^{\circ}$ 12, (Dec. 2005), pp. 2128-2141, ISSN 0018-9219. 
[2] Cavallini, A. and Montanari, G.R. "Compensation strategies for shunt active filter control", IEEE Transactions on Power Electronics, vol. 9, $\mathrm{n}^{\circ}$ 6, (Nov. 1994), pp. 587-593, ISSN 0885-8993.

[3] Chen, B.S., and Joós, G. "Direct power control of active filters with averaged switching frequency regulation". IEEE Transactions on Power Electronics, vol. 23, no 6, (Nov.2008), pp. 2729-2737, ISSN 0885-8993.

[4] A Switch Capacitor KVAr and Selective harmonic current Compensator, CC Marouchos M. Darwich. Evdokimou, UPEC2013, Dublin Ireland

[5] N. Senthilnathan and T. Manigandan, "A Novel Control Strategy for Line Harmonic Reduction using Three Phase Shunt Active Filter with Balanced and Unbalanced Supply" EJSR ISSN 1450-216X Vol.67 No.3 (2012), pp.

[6] S.Chakraborty, S Annie, M.A. Razzak "Design of a single buck and Boost Convertrr for Photovoltaic application" 3rd International Conference on Informatics ., Electronics \& VISION 2014.

[7] Yu Tang, Yaohua He, Xianmei Dong “ Avtive-Boost Invertyer With Coupled Inductors 3rd International Conference on Informatics, Electronics \& VISION 2014
[8] A new Concept for a Multilevel Switched Capacitor sinusoidal Grid Connected Inverter, CC Marouchos M. Darwish L. Diomidou, UPEC2013, Dublin Ireland.

[9] Cassiano Rech, Humberto, Pinheiro, Hilton and A. Griindling, HClio L "Analysis and Comparison of Hybrid Multilevel Voltage Source Inverters", Power Electronics Specialists Conference, 2002. pesc 02. 2002 IEEE 33rd Annual.

[10] Fang Z. , "Generalized Multilevel Inverter Topology with Self Voltage Balancing”, Industry Applications Conference, 2000. Conference Record of the 2000 IEEE.

[11] N Benaifa, "Parallel operated Inverers as a Multilevel Case", Electrical and Computer Engineering, 2008. CCECE 2008. Canadian Conference.

[12] Marouchos, C : "The switching Function: Analysis of Power Electronic Circuits", IEE, London, 2006, ISBN-10 086341351X, ISBN-13: 978086341351-3. 